\title{
ESTRUTURA DO BIOFILME DENTAL ANALISADA POR MICROSCÓPIO DE FORÇA ATÔMICA
}

Danielle Gomes Lopes LIECHOCKI; Giulia Yuriko TANAKA; Aline Okamoto YOSHIZUMI; Cecília FERREIRA; Elaine Machado BENELLI

O esmalte dental é formado por prismas que contém cristais de hidroxiapatita. Após a higienização, o esmalte é recoberto pela película adquirida que contém íons e proteínas salivares que aderem à superfície dental. Quando o hospedeiro ingere sacarose, Streptococcus mutans produz polissacarídeos extracelulares e adere à película formando o biofilme dental. Neste trabalho, o biofilme dental formado in situ em presença e ausência de sacarose foi caracterizado por microscopia de força atômica (MFA). O biofilme dental foi formado sobre blocos de esmalte fixados no palato de dispositivos intra-orais que foram mergulhados oito vezes ao dia em solução de sacarose $20 \%$ para avaliar a estrutura do biofilme formado até 10 dias de tratamento. Em seguida, o bloco de esmalte contendo biofilme foi analisado por MFA operando em modo dinâmico e de contato. Os resultados mostraram que na ausência de sacarose estruturas de aproximadamente 134nm, semelhantes a cristais de hidroxiapatita, foram observadas, enquanto que na presença de sacarose, os cristais desaparecem, mas bactérias na forma de cocos de dimensões aproximadas de $865 \mathrm{~nm}$ que são compatíveis com $S$. mutans. Os resultados sugerem que a MFA, associada ao modelo in situ, permite acompanhar as alterações estruturais do biofilme dental formado sobre diferentes condições nutricionais. 